\title{
Intergenerational Effects of Guaranteed Pension Contracts
}

\author{
Trond M. Døskeland and Helge A. Nordahl \\ Department of Finance and Management Science, Norwegian School of Economics and Business \\ Administration, Helleveien 30, Bergen 5045, Norway. \\ E-mail: trond.doskeland@nhh.no
}

In this paper we show that there exist intergenerational cross-subsidization effects in guaranteed interest rate life and pension contracts as the different generations partially share the same reserves. Early generations build up bonus reserves, which are left with the company at expiry of the contract. These bonus reserves function partly as a subsidy of later generations, such that the latter earn a risk-adjusted return above the risk-free rate. Furthermore, we show that this subsidy may be large enough to explain why late generations buy guaranteed interest rate products, which otherwise would not have been part of the optimal portfolio allocation. The Geneva Risk and Insurance Review (2008) 33, 19-46. doi:10.1057/grir.2008.3

Keywords: portfolio choice; life and pension insurance; interest rate guarantees

Jel classification: G11; G13; G22

\section{Introduction}

Many households rely on life and pension (L\&P) contracts to finance their retirement expenditures. We show that there exist an intergenerational crosssubsidization effect in guaranteed interest rate L\&P contracts as the different generations partially share the same reserves. Because of the bonus reserves described below, early generations subsidize later generations, such that the latter earn a risk-adjusted return above the risk-free rate.

Previous research on L\&P contracts has focused on the risk sharing between one customer and the company as well as pricing one customer's claim on the company. However, at any given point of time, the customer base of a company consists of many customers at different stages of the contract life cycle. In this paper we focus on the relationship between different generations of customers and the company.

We use a simple contract with annual guaranteed return in the fashion of Miltersen and Persson (2003). There is a large literature pricing L\&P contracts. Some contributions illustrating different design of contracts are papers by Grosen and Jørgensen (2000), Hansen and Miltersen (2002), and Miltersen and Persson 
(2003). Our main complicating element will be the existence of a bonus reserve, which consists of funds allocated, but not yet guaranteed, to customers. This bonus reserve may or may not be individualized, so that customers may only receive a part, if any, of their proportional share at the expiry of the contract.

In a setting where different generations share the same reserves, at least two sources of cross-subsidization may occur. The bonus reserve is typically left in the company from the expiring generation to future generation. However, in the other direction is the effect that the new generation in a default scenario may end up paying a part of the obligation to the old generation. To test this hypothesis we calculate the expected risk-adjusted return (under the equivalent martingale measure $Q$ ) of the contract for each generation, given that the owners of the company are not able to extract any capital beyond the riskadjusted return on capital. We find that the former effect is the larger, such that the net effect is that the later generations end up with the higher return. ${ }^{1}$ The difference in return seems to be fairly small on an annual basis, but still significant over the lifetime of the contract. Changes in parameters have an impact on the size of the cross-subsidization, in particular the spread between risk-free interest rate and the guaranteed rate of return, as well as the crediting rate of the bonus reserve and the asset allocation contributes to these changes. The youngest generations benefit from high spreads, high allocations to the bonus reserves, and a conservative asset allocation, while opposite is the case for previous generations.

Risk-adjusted return different from cost of capital may in general raise the issue of arbitrage. However, in this case investors are normally households with a limited set of investment opportunities. Furthermore, shortselling pension contracts is not normally feasible, even though some repurchasing arrangements exist.

Most L\&P companies have existed for ages. ${ }^{2}$ At the time of investment of the first generations (which we will later show end with a return below cost of capital), only a limited set of investment opportunities existed, compared to today's market. Furthermore, there were no closed-fund investment opportunities, hence they had no way to contractually prevent new generations from entering the customers' fund of the L\&P company.

Among the latest generations one could think of an arbitrage opportunity of buying the pension product and shortselling a replicating portfolio. However, L\&P companies in general only allow for private investors or beneficiaries with limit investments, hence the shortselling capacity in a replicating portfolio is limited, and transaction costs will be high, particularly as the replicating portfolio also needs to be continuously rebalanced. Furthermore, L\&P

\footnotetext{
${ }^{1}$ In our calibrated benchmark case bankruptcies only play a marginal role.

${ }^{2}$ Even though mergers and acquisitions frequently occur, the portfolios tend to prevail.
} 
companies typically have a low degree of transparency in their investment, and therefore it will be difficult to find the optimal arbitrage strategy.

The cross-subsidization described above also provides an alternative explanation of the problem "why do households buy pension insurance?" Only a few papers look at the welfare effects of the contracts. Brennan (1993) elaborates on the classical point made by Borch (1962) that guaranteed products will lead to a welfare loss. According to Borch, we cannot explain the existence of these saving vehicles within an one-generation expected utility framework with HARA utility, as these contracts have a non-linear pay-out function. Jensen and Sørensen (2001), Consiglio et al. (2006), and Døskeland and Nordahl (2008) build on this point by quantifying the effects in various cases of interest rate guarantees. However, previous research assumes that all generations receive the same return. In the second part of this paper we expand the previous welfare studies by testing the impact of generation-based return in an individuals' portfolio choice model. Customers can choose between investing directly or indirectly via the guaranteed products.

We find that even when assuming standard preferences (constant relative risk aversion) utility maximization shows that pensions will be part of optimal portfolio. New generations benefit from the cross-subsidization. In addition, the return depends on market return during the same period as investment, but also during previous periods. Because of this, there will be an intergenerational diversification effect reducing the risk.

Explaining the choices of the previous generations is more difficult in our model. However, while today there exist a wide set of opportunities, previous generations clearly had a limited choice. It may be that in previous times guaranteed rate L\&P insurance products were purchased simply due to the lack of other alternatives.

The rest of our paper is organized as follows. In Section 2, we describe the multi-generation model of a pension insurance product. Section 3 provides support for our parametrization of the model. The numerical results of the cross-subsidization are given in Section 4, along with selected sensitivities. In Section 5, we provide a simple portfolio choice model and show optimal asset allocation for each generation, while Section 6 gives the conclusion and suggestions for further research in this area.

\section{The model}

In this section we formalize the modelling framework. We first describe the economy, then the L\&P company including the insurance contract offered to households and finally the households. An overview of the parameters of the model is shown in Table 1. 
Table 1 Definitions

The economy

Value of one unit of the equity index at time $t$ where all dividends are immediately reinvested into the index

Value of one unit of the risk-free bond account at time $t$

Constant risk-free rate

Constant expected return on the equity index

Constant volatility of the equity index

Standard Brownian motion

$S_{t}$
$D_{t}$
$r$
$\mu$
$\sigma$
$Z_{t}$

The company

Value of the total asset portfolio at time $t$

Constant proportion of total asset portfolio, $A_{t}$, invested in the equity index

The equity of the company at time $t$

The mathematical reserves (customers' funds) at time $t$

The bonus account (bonus reserves) at time $t$ (to be further described)

Final wealth from insurance product to generation $t-T$ at time $t$

Cash flow to the investors of the company at time $t$

The proportion of equity to total assets at time $t=1, E_{1} / A_{1}=(1-\alpha)$

The constant guaranteed rate

The proportion split of the remaining total profit (after guarantee and “ $\alpha$ ” split)

$A_{t}$
$\theta$
$E_{t}$
$L_{t}$
$B_{t}$
$I_{t}^{--T}$
$C F_{t}$
$(1-\alpha)$
$g$
$\delta$

$b$
$p$
$V$

Payout ratio of bonus reserve

Discounted value of all cash flows

\section{The households}

Coefficient of relative risk aversion

Overlapping generations of households, indexed by $h=1,2, \ldots, H$

Term of the policy

Wealth of generation $h$ at time $t$

The mathematical reserves of households of generation $h$ at time $t$

Growth rate of the households' aggregate initial investments

\section{The economy}

We assume a standard no-arbitrage economy with two assets, a risk-free bank account, $D_{t}$ and a risky equity index, $S_{t}$. The dynamics of the asset classes is then given by:

$$
\begin{gathered}
\mathrm{d} D_{t}=r D_{t} \mathrm{~d} t, \quad D_{0}=d, \\
\mathrm{~d} S_{t}=\mu S_{t} \mathrm{~d} t+\sigma S_{t} \mathrm{~d} Z_{t}, \quad S_{0}=s,
\end{gathered}
$$


Time t

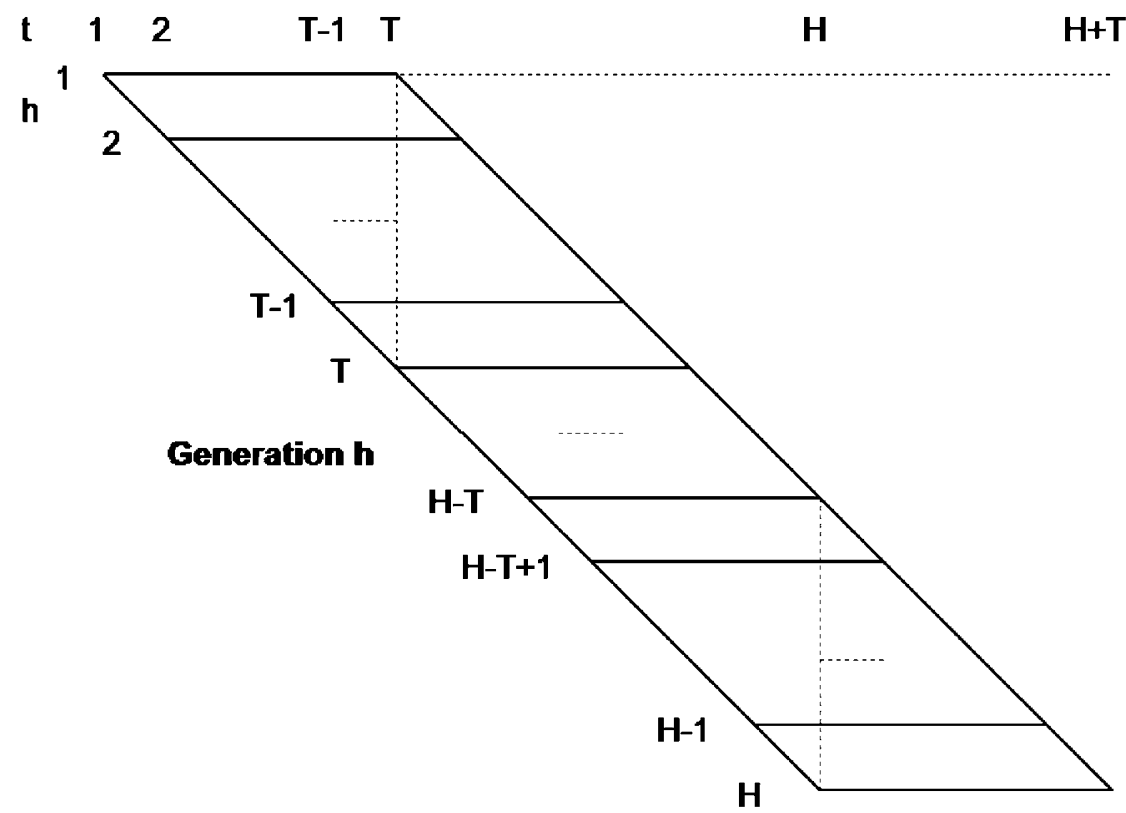

Figure 1. Generations.

where $r$ is the constant risk-free interest rate, $\mu$ the constant expected return on the equity index, $\sigma$ the constant volatility of the equity index, and $Z_{t}$ is a standard Brownian motion.

We create a model with $H$ overlapping generations of households, indexed by $h=1,2, \ldots, H$. The $x$-axis in Figure 1 illustrates the time line. On the $y$-axis the different generations are listed. Each generation uses the pension system for $T$ periods. The wealth of the household of generation $h$ at time $t$ is given by $W_{t}^{h}$. We explore the implications of heterogeneity across generations.

\section{The company}

We assume that there exists a financial intermediary, which we will refer to as "the company", offering pension contracts. The balance sheet development of the company is illustrated in Tables 2 and 3. At time 1 only shareholders and generation 1 have invested in the company. The equity is then a proportion $(1-\alpha)$ of the total assets, $A_{1}$, of the company. The bonus reserve $B_{1}$ is zero at the initiation of the company. At the end of each subsequent year shareholders will keep the proportion of equity constant at the level $(1-\alpha)$, either by taking out dividends or by paying in capital. Furthermore, there will be a bonus 
Table 2 Balance sheet at time $t=1$

\begin{tabular}{ll}
\hline Assets & Liabilities \\
\hline$A_{1}$ & $E_{1}=(1-\alpha) A_{1}$ \\
& $B_{1}=0$ \\
& $L_{1}=\alpha A_{1}$ \\
\hline
\end{tabular}

The table shows the balance sheet of the insurer at the set up date.

Table 3 Balance sheet at time $t$

$\left.\begin{array}{ll}\hline \text { Assets } & \text { Liabilities } \\ \hline A_{t} & E_{t}=(1-\alpha) A_{t} \\ & B_{t} \\ & L_{t}^{1} \\ & L_{t}^{2} \\ \cdots & L_{t}^{H}\end{array}\right\} L_{t}$

The table shows the balance sheet of the insurer at time $t$.

reserve $B_{t}$, and all generations will have their specific allocated reserve $L_{t}^{h}$ for generations $h=1, \ldots, H$. The sum of mathematical reserves for all generations is labelled $L_{t}$. The balance sheet at time $t$ is shown in Table 3 .

A proportion $\theta_{t}$ of the company's assets is invested in the equity index. We will assume that the proportion of the equity index is fixed, i.e., that $\theta_{t}=\theta$. The dynamics of the total asset portfolio $A_{t}$ under the real probability measure $P$ is then given by

$$
\mathrm{d} A_{t}=\left(r A_{t}+\theta(\mu-r) A_{t}\right) \mathrm{d} t+\theta A_{t} \sigma \mathrm{d} Z_{t}, \quad A_{1}=a .
$$

In the discrete world we transform Eq. (3) to

$$
A_{t}^{c u m}=A_{t-1} e^{\left(r+\theta(\mu-r)-\frac{1}{2} \theta^{2} \sigma^{2}+\theta \sigma\left(Z_{t}-Z_{t-1}\right)\right)},
$$

or under the equivalent martingale measure, $Q$ :

$$
A_{t}^{\text {cum }}=A_{t-1} e^{\left(r-\frac{1}{2} \theta^{2} \sigma^{2}+\theta \sigma\left(Z_{t}^{Q}-Z_{t-1}^{Q}\right)\right)} .
$$

Superscript cum indicates values before annual settlements. 


\section{The pension contract}

In the setup of our model, we concentrate on the financial features of the contract, regarding the savings element as the most important. ${ }^{3}$ Even though there are no international standard contracts we try to make a simplified contract that will be close to products sold in most European (and some nonEuropean) countries.

We assume that all parameters of the contracts are fixed at set up date. Furthermore, we assume correct initial pricing from the company's perspective, meaning that the company's average risk-adjusted return over the whole life time equals the risk-free rate.

The basis for calculating return to customers is the guaranteed rate of return. We use annual guarantees rather than lifetime guarantees, ${ }^{4}$ hence each year the mathematical reserves will increase by a fixed rate $g$. In addition to that, customers may receive a bonus if the total return on mathematical reserves and equity of the company exceeds $g$. The bonus will then be the surplus, less a proportional share $(\alpha \delta)$ to shareholders to compensate for capital inserted and risk assumed by shareholders, as well as a proportional share $b$ to the bonus reserves described below.

In order to provide buffers for companies to meet bad years in the security markets, regulators in most countries allow for (and to a certain extent require) the build up of buffers of capital that are yet to be allocated to the mathematical reserves. These buffers have different forms, importance and names from country to country, e.g., bonus reserves, value adjustment reserves, unrealized gains (reserves), fund for future appropriations, etc. We name them bonus reserves, $B_{t}$. Bonus reserves can be used if the achieved return is not sufficient of covering guaranteed returns. ${ }^{5}$ Furthermore, bonus reserves are not allocated to any specific generation. At the expiry of the contract, each generation will only be able to extract a part $p$ of their proportional share of the bonus reserves.

\footnotetext{
${ }^{3}$ This means we will not cover pure actuarial risk elements, like mortality risk, disability risk, longevity risk, etc., or any type of administrative costs. Neither will we cover any part of the premium set aside to cover such elements, which means that we assume that the full initial payment from customers go into a form of savings account. Our contract will be based on a single premium and a single payment at expiry of the contract.

${ }^{4}$ As used for example by Grosen and Jørgensen (2000).

${ }^{5}$ In practice, allocation to bonus reserves is done in a number of ways, e.g., through allocating a proportion of bonuses each year, allocating unrealized gains on various types of securities, increasing the funds in the same rate as the other reserves, bringing the bonus reserve to a target level, etc. In order to find a common model, we use the simple allocation mechanism (proportion of declared bonuses) described by Miltersen and Persson (2003).
} 


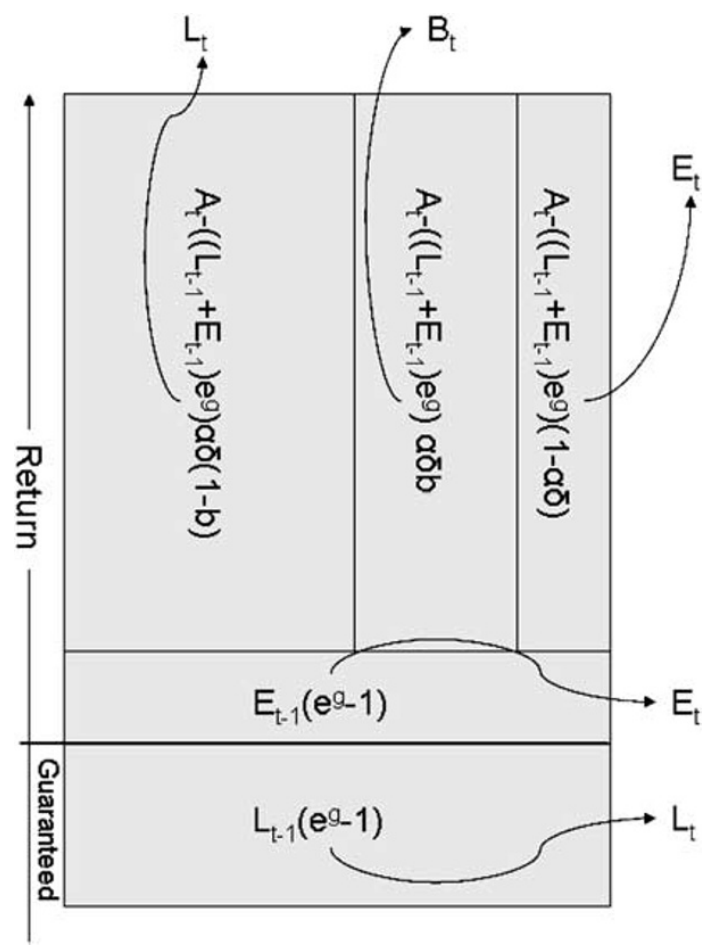

Figure 2. Allocation of return. The figure illustrates how return is split between different types of capital. The $x$-axis shows different stakeholders (customers, $L$, owners, $E$ and bonus account, $B$ ). The $y$-axis illustrates the return on the total assets. The first part of the return (guarantee) is allocated to the customer reserve, then a part is allocated to equity, while return above is split among customer reserve, bonus reserve, and equity.

In our model we credit the bonus reserves by a proportion of declared bonuses, $b$. Figure 2 illustrates the allocation rules. The bottom part of the return covers the guaranteed amount. If returns exceed the level of the guarantee, an amount will be used to cover a similar return on shareholders' capital. Then, if there is still something left, the remaining return will be split proportionally among equity, mathematical reserves, and bonus reserves.

The model is initiated at time $t=1$, where we define

$$
\begin{aligned}
& L_{1}^{1}=L_{1}=\alpha A_{1}, \\
& E_{1}=(1-\alpha) A_{1}, \\
& B_{1}=0 .
\end{aligned}
$$


We then initiate each generation at time $t=h$, when generation $h$ does their investment:

$$
L_{t}^{h}=L_{1}^{1}(1+v)^{h-1} \quad \text { for all } t \text { and } h \text { such that } t=h,
$$

where $v$ is growth rate of the households' aggregate initial investments. We assume that $v$ is deterministic and not related to the profitability of the product. In a perfect market customers choice of investment will be an endogenous decision dependent on the expected return of the product. However, as there may be factors not covered in the model (e.g. limited investment opportunities in some periods, lack of information or limited freedom to choose pension vehicle if part of employers' contract), we find the assumption of exogenous growth, i.e., that customers make no independent investment decisions, to be realistic.

Each year after the initial year, generation $h$ will lose the guaranteed amount if and only if total assets in the company are insufficient to cover the guaranteed amounts of generation $h$ and all previous generations. ${ }^{6}$ If any generation lose part of (or all of) the guaranteed amount, the company will be declared bankrupt. However, at this point we assume that the company will be recapitalized by new owners and continue operating. In this case the total liabilities, $L_{t}$, will be limited to the value of the asset before recapitalization, $A_{t}$.

If assets are sufficient to cover the guaranteed amount to all generations, a corresponding return on the equity, and preservation of the bonus reserve, the customers earn a bonus. The bonus is the generation's proportional share of the mathematical reserves, multiplied by the customers' proportional share of the capital $(\alpha)$, the customers' share of profits $(\delta)$, the share being credited the mathematical reserves $(1-b)$, and the surplus in itself. Hence, for all $t$ and $h$ such that $h<t \leqslant h+T$

$$
L_{t}^{h}= \begin{cases}0 & \text { if } A_{t} \leqslant \sum_{j=1}^{h-1} L_{t-1}^{j} e^{g}, \\ A_{t}-\sum_{j=1}^{h-1} L_{t-1}^{j} e^{g} & \text { if } A_{t} \leqslant \sum_{j=1}^{h} L_{t-1}^{j} e^{g}, \\ L_{t-1}^{h} e^{g} & \text { if } A_{t} \leqslant\left(L_{t-1}+E_{t-1}\right) e^{g}+B_{t-1}, \\ L_{t-1}^{h} e^{g}+\frac{L_{t-1}^{h}}{L_{t-1}} \alpha \delta(1-b) & \text { if } A_{t}>\left(L_{t-1}+E_{t-1}\right) e^{g}+B_{t-1} . \\ \left(A_{t}-\left(L_{t-1}+E_{t-1}\right) e^{g}+B_{t-1}\right) & \end{cases}
$$

\footnotetext{
${ }^{6}$ Thus, the old generations will have the priority if the company risks default, but on the other hand they will leave some amount (part of the bonus reserve) in the company when their contract expire.
} 
Finally, we let $L_{t}^{h}$ be zero at all times where generation $h$ has no investments:

$$
L_{t}^{h}=0 \quad \text { for all } t \text { and } h \text { such that } t>h+T \text { or } t<h .
$$

We can then sum all the mathematical reserves before cash flows made at the year end (marked by superscript cum):

$$
L_{t}^{c u m}=\sum_{j=1}^{t-1} L_{t}^{j}
$$

The bonus account is used when return on assets are not sufficient to cover the guarantee. Hence, if assets at the end of the year is low, the bonus account will be zero, or at least lower than the previous year. If assets are high, the bonus account will be credited a proportion $b$ of the total bonus to customers. More formally,

$$
B_{t}^{c u m}= \begin{cases}0 & \text { if } A_{t} \leqslant L_{t-1} e^{g}+E_{t-1} \\ A_{t}-L_{t-1} e^{g}-E_{t-1} & \text { if } A_{t} \leqslant L_{t-1} e^{g}+E_{t-1}+B_{t-1}, \\ B_{t-1} & \text { if } A_{t} \leqslant L_{t-1} e^{g}+E_{t-1} e^{g}+B_{t-1}, \\ B_{t-1}+\alpha \delta b\left(A_{t}-\left(L_{t-1} e^{g}+E_{t-1} e^{g}+B_{t-1}\right)\right) & \text { if } A_{t}>L_{t-1} e^{g}+E_{t-1} e^{g}+B_{t-1} .\end{cases}
$$

When contracts expire, customers may be allowed to extract a proportion $p$ of their proportion of the bonus account. Hence, the new bonus account at the beginning of next year will be

$$
B_{t}=B_{t}^{\text {cum }}\left(1-\frac{L_{t}^{t-T}}{L_{t}^{\text {cum }}} p\right)
$$

and the final wealth from the insurance product to the customer becomes

$$
I_{t}^{t-T}=L_{t}^{t-T}+B_{t}^{\text {cum }} \frac{L_{t}^{t-T}}{L_{t}^{\text {cum }}} p .
$$

After deposits from new customers and withdrawals for old ones with expiring contracts, the new mathematical reserves at the beginning of the next year will become

$$
L_{t}=L_{t}^{c u m}+L_{t}^{t}-L_{t}^{t-T} .
$$

Equity at the end of year can be determined residually as

$$
E_{t}^{\text {cum }}=A_{t}^{\text {cum }}-L_{t}^{\text {cum }}-B_{t}^{\text {cum }} .
$$


At the beginning of the next year we assume the company to be recapitalized, such that the proportion of equity to mathematical reserves stays constant over time. Hence,

$$
E_{t}=L_{t} \frac{(1-\alpha)}{\alpha}
$$

and assets at the beginning of next year becomes

$$
A_{t}=L_{t}+B_{t}+E_{t}
$$

Now, the cash flow to shareholders can be determined simply as the difference between equity at the end of a year and at the beginning of the next year:

$$
C F_{t}=E_{t}^{c u m}-E_{t}
$$

We assume that this cash flow can be freely traded in the form of stocks in the company, as opposed to the contract in itself, which is only to a very limited extent a tradable asset, it can only be purchased by individuals, has restrictions on short selling and normally includes higher transaction costs and limited transparency. Hence the value at time $t=1$ is

$$
V=\sum_{t=2}^{T+H} E^{Q}\left[C F_{t}\right] e^{-r(t-1)} .
$$

For annual guarantees with bonus reserves closed form solutions of "fair" contracts are unavailable, and we have to rely on numerical solutions using Monte-Carlo simulations. We define a fair contract as a contract where investors of the insurance company will be indifferent to whether the company makes the contract or not. To be able to find fair $\delta$ for a given set of the control variables, $\alpha, \theta, g, b$, we simulate $m$ paths of the cash flows and calculate the respective values of the equity under the risk-neutral measure, $Q$,

$$
E_{1}=V=\sum_{t=2}^{T+H} e^{-r(t-1)} E^{Q}\left[C F_{t}\right] .
$$

Since the value of equity is monotonically decreasing in $\delta$ and twice differentiable, i.e., satisfying Theorem 2.1, Judd (1998, p. 150), we can utilize Newton's method to find a fair $\delta$ for each contract.

We solve the model by numerical simulations, using $m=100,000$ MonteCarlo simulations. We are then able to find a mean value of the contract at expiry date for each generation, $I_{h+T}^{h}$. We also calculate the mean annual riskadjusted return of generation $h, \tilde{r}^{h, Q}=\ln \left(I_{h+T}^{h} / L_{h}^{h}\right) / T$. 
30

\section{The households}

We assume that households can be represented by a CRRA utility function with a relative risk aversion coefficient $\gamma$. Then the utility of generation, $h$, can be described as a power utility function on the form

$$
u\left(W^{h}\right)=\frac{1}{1-\gamma}\left(W_{h+T}^{h}\right)^{1-\gamma} .
$$

The households' maximization problem for each generation will be distributing the wealth between the risky and risk-free asset as well as the insurance product. The weights of the portfolio allocated to each of the assets are named $\omega_{S}$ (weight of risky asset), $\omega_{D}$ (weight of the risk-free asset), and $\omega_{I}$ (weight of the insurance product). We assume a borrowing constraint and no short-selling, such that all weights are non-negative. Furthermore, we assume no continuous rebalancing. Even though the risky and risk-free assets are tradeable, the insurance asset can typically not be traded, at least not in portions, before expiry. The optimization problem can be formalized as

$$
\max _{\omega_{S}, \omega_{D}, \omega_{I}} E\left[u\left(W^{h}\right)\right]
$$

subject to

$$
\begin{gathered}
W^{h}=\bar{W}^{h}\left(\omega_{S} \frac{S_{h+T}}{S_{h}}+\omega_{D} \frac{D_{h+T}}{D_{h}}+\omega_{I} \frac{I_{h+T}^{h}}{L_{h}^{h}}\right), \\
\omega_{S}+\omega_{D}+\omega_{I}=1, \\
\omega_{S}, \omega_{D}, \omega_{I} \geqslant 0 .
\end{gathered}
$$

We standardize the initial wealth $\bar{W}^{h}$ to 1 . Furthermore we know that $D_{h+T} / D_{h}$ is simply the risk-free rate continuously compounded and we can replace it by $e^{r T}$. Hence we get from Eq. (23):

$$
W^{h}=\omega_{S} \frac{S_{h+T}}{S_{h}}+\omega_{D} e^{r T}+\omega_{I} \frac{I_{h+T}^{h}}{L_{h}^{h}} .
$$

The optimization problem is solved using the same 100,000 Monte-Carlo simulations mentioned above, in each case calculating the utility under the real 
Table 4 Calibration

Parameters of the model

Notation Benchmark case

The economy

Risk-free rate

Expected return on the equity index

Volatility of the equity index

$r \quad 4.0 \%$

$\mu \quad 8.0 \%$

$\sigma \quad 16.0 \%$

\section{The company}

Proportion of total asset portfolio, $A_{t}$, invested in the equity index $\quad \theta \quad 20 \%$

Mathematical reserves to total assets at time $t=1\left(\alpha=L_{1} / A_{1}\right) \quad \alpha \quad 90 \%$

The proportion split of the remaining total profit to the households

Proportion of declared bonuses credited the bonus reserves $B_{t}$

Payout ratio of bonus reserve

g $\quad 2.0 \%$

$\delta \quad 97.11 \%$

b $\quad 30 \%$

p $\quad 36 \%$

\section{The households}

Overlapping generations of households, indexed by $h=1,2, \ldots, H$

$\begin{array}{cc}H & 80 \\ T & 20 \\ v & 2.0 \% \\ \gamma & 5\end{array}$

Trowth rate of the households' aggregate initial investments

Coefficient of relative risk aversion

The table provides the benchmark case parameter values that are used to conduct the numerical analysis.

probability measure. The optimization problem is solved for each generation separately. The results are given in Section 5.

\section{Calibration}

Table 4 reports our benchmark parameter values. We calibrate our model using data for a simplified, but typical contract in several European countries.

\section{Parameters of the economy}

As our risk-free rate, $r$, we use the long-term rate of German government bonds. At 1 January 2006, the 30 -year rate was 3.62 per cent. ${ }^{7}$ We use 4.0 per cent as our risk free rate. For the stock return process we consider a mean equity premium, $(\mu-r)=4.0$ per cent, and a standard deviation, $\sigma=16$ per cent. Considering an equity premium equal to 4 per cent as opposed to the historical 6 per cent is a fairly common choice in this literature, see e.g., Cocco et al. (2005), Yao and Zhang (2005), or Gomes and Michaelides (2005).

\footnotetext{
${ }^{7}$ Source: Datastream.
} 
Table 5 Current guaranteed interest rates in Continental Europe

\begin{tabular}{lll}
\hline Country & \multicolumn{2}{l}{ Current guaranteed rate $(\%)$} \\
\hline Austria & 2.25 & From 1 Jan 2006 \\
Belgium & 3.75 & Other rates for durations shorter than 8 years \\
Denmark & 2.0 & \\
France & 2.5 & $3 \%$ for durations shorter than 8 years \\
Finland & 2.5 & \\
Germany & 2.75 & From 1 Jan 2006 \\
Italy & 2.0 & \\
Netherlands & 3.0 & Proposed reduction to $2.75 \%$ for some contracts \\
Norway & 3.0 & \\
Sweden & 2.75 & Lower rates used in contracts with no mandatory guarantees \\
Switzerland & 2.5 &
\end{tabular}

The table shows current (2006) guaranteed interest rates in continental Europe.

Sources: CEIOPS, BPV (Switzerland).

\section{Guarantees}

According to the third European life assurance directive the guaranteed interest rate shall be maximum 60 per cent of the interest rate of government bonds of the same currency, without defining this further. ${ }^{8}$ National authorities are left to make more detailed rules. However, currently most national regulations allow higher guaranteed rates than 60 per cent of most euro government bond rates. A survey is provided in Table 5. Assuming that national regulators will eventually change their regulations in the direction of the third European life assurance directive, we let the guaranteed rate be 2.0 per cent.

\section{Bonus reserves}

We illustrate our discussion on bonus reserves with the quite complicated German way of reserving, as described by Allianz in their presentation to investors at the Allianz Capital Markets Day 14 July 2005. ${ }^{9}$ The 2004 surplus of Allianz was in total 4.9 billion euros, net of taxes. ${ }^{10}$ Of this, 3.2 billion were accounted on balance sheets, while 1.7 billion was related to the development of hidden reserves.

${ }^{8}$ See article 17.

${ }^{9}$ Presentation downloadable at www.allianz.com.

${ }^{10} \mathrm{We}$ do not include development of off-balance sheet items, as we assume these to be expected to be close to zero in the future. 
From the total surplus, 0.2 billion euros were transferred to the equity. This gives a $\delta$ of 93.8 per cent, which, however, has little relevance to us, as $\delta$ will be used as the balancing parameter for achieving correct pricing over the product life-cycle. In total, 2.0 billion euros were transferred to the mathematical reserves. This corresponds to $b=33.3$ per cent. We round this and use $b=30$ per cent as our base case.

The bonus reserves in Allianz can be split into several parts. In addition to the split between on-balance-sheet items (reserves for bonuses, RfB) and off-balance sheet items (hidden reserves), it will be useful to split the RfB into allocated RfB and terminal bonus fund (which can be individualized) and free RfB (which cannot be individualized). We assume that at expiry of the contracts, customers will only receive their proportional parts of the individualized funds. For Allianz, this corresponds to $p=36$ per cent, which we will use as our base case. We note, however, that individualized bonus fund are only common in some European countries, hence we will also show scenarios with $p=0$.

\section{Asset allocation and capital structure}

In Table 6 we show that the average allocation for European L\&P companies is 3 per cent in real estate, 22 per cent in equity, and 74 per cent in bonds. We regard real estate as close to fixed income, thus based on European data we set our rounded asset allocation parameter, $\theta=20$ per cent. As the asset allocation

Table 6 Asset allocation life companies 2004

\begin{tabular}{lccc}
\hline & Real estate $(\%)$ & Equity $(\%)$ & Bonds $(\%)$ \\
\hline Austria & 4.0 & 33.9 & 62.2 \\
Belgium & 0.9 & 19.7 & 79.4 \\
Germany & 2.8 & 28.7 & 68.5 \\
Denmark & 2.6 & 32.8 & 64.6 \\
Finland & 8.1 & 30.3 & 61.6 \\
France & 2.9 & 11.3 & 85.8 \\
Ireland & 5.0 & 18.4 & 76.6 \\
Italy & 0.4 & 14.9 & 84.7 \\
Netherlands & 7.7 & 16.4 & 75.9 \\
Norway & 10.4 & 17.4 & 72.2 \\
Average & 3.4 & 22.5 & 74.1 \\
\hline
\end{tabular}

The table shows the asset allocation for European life companies for 2004. The average is value weighted. Equity is the sum of shares, variable-yield securities, units in unit trusts and investments in affiliated enterprises. Bonds consists of debt securities, fixed income securities, investment pools, mortgage loans, other loans, deposits with credit institutions and deposits with ceding enterprises. Source: CEIOPS. 
typically changes over time, we provide sensitivities to this in the section 'Sensitivities to the benchmark case'.

Based on data from CEIOPS value weighted average equity share $(1-\alpha)$ of main countries is 9.2 per cent. We use $(1-\alpha)=0.1$ or $\alpha=0.9$.

\section{Parameters of the households}

In our model we use a single premium contract with a duration $T$ of 20 years. In order to get a "going-concern-state", where old contracts expire, but at the same time new ones are written, it is necessary to use more than 40 generations. We use as number of generation $H=80$.

Even in a "going-concern-state" there will be some growth in the assets of the company due to the increase in premiums paid by the newer generation. This is due to increase in population, inflation, and real growth rates. The population growth in Europe is assumed to be zero or even negative in the future. ${ }^{11}$ Assuming no long-term real growth we limit our growth rate $v$ to the inflation rate of 2 per cent as is the target of ECB.

We start by presenting results for a quite common relative risk aversion $\gamma=5$ (as e.g. see Gomes and Michaelides, 2005). As reference points for our sensitivity analysis we use $\gamma=3$ (as e.g. see Dammon et al., 2004) and $\gamma=10$ (e.g. Cocco et al., 2005).

\section{Intergenerational cross-subsidization}

\section{Result of the benchmark case}

The main result of our benchmark case is given in Figure 3. We find that the expected risk-adjusted return, $\tilde{r}^{h, Q}$; is monotonically increasing with respect to generations and above the risk-free rate from generation 42 . The return when old customers are of the last 20 generations seems unrealistically high. This is due to the fact that these generations remain invested during the build-down period. At this point of time customers are able to extract from the company bonus reserves built up by all previous generations. This extraction may appear unrealistic, as companies will typically sustain.

Furthermore, we find low returns to generations in the build-up phase of the first 20 generations. Customers in this phase should rather look for alternative investments in other product. In practise we see very few new L\&P companies selling guaranteed products in mature markets. Recently, new companies in

\footnotetext{
${ }^{11}$ According to UN World Population 2004. See http://www.unpopulation.org.
} 


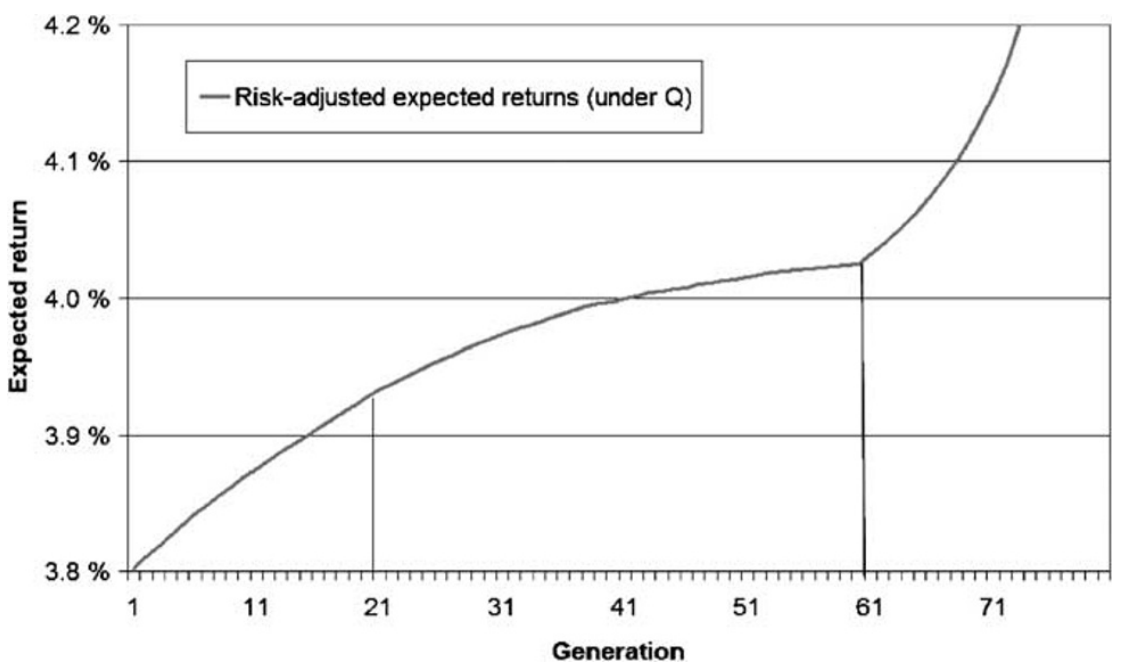

Figure 3. Expected return for different generations. The figure shows expected annual riskadjusted return of the insurance contract for different generations 1-80. This return can be compared to the risk-free rate of 4 per cent.

Western European markets, for example Mediolanum and MLP, have preferred unit-linked and other non-guaranteed products.

We will particularly focus on the difference between early and late generations in the going-concern phase from generation 20 to 60 . We find an expected risk-adjusted return of 3.93 per cent for generation 20, compared to 4.03 per cent for generation 60 . This return difference may seem small, but in a 20 -year perspective it will still be significant, corresponding to an initial value difference of 2 per cent. ${ }^{12}$ Tests with 200 generations show that the riskadjusted return will converge to a level of approximately 4.06 per cent from generation 80 . For further generations returns will be stable until the last 20 generations, which will still benefit from the build-down period.

In Figure 4 we illustrate the risk of each generation, measured by the standard deviation of the average annual return. We find that the risk increases in the same fashion as the expected risk-adjusted return. Economically it seems that the return overcompensates for the risk, yielding a return above the riskadjusted rate if there is enough risk taken.

${ }^{12}$ We find this value by calculating the total initial value $e^{(\tilde{r} Q-r) T}$, where $\tilde{r}^{Q}$ is the mean riskadjusted return and $r$ is the risk free rate. We find this value to be approximate 1.006 in the case of generation 60, and 0.986 in the case of generation 20, giving a difference of 2 per cent. 




Figure 4. Standard deviation for different generations. The figure shows the standard deviation of the annual risk-adjusted return of the insurance contract.

The technical explanation is that each generation assumes investment risk of the investment period of the previous generation through the bonus reserve. If a generation faces high returns in the stock market it will leave behind a high bonus reserve causing high expected returns for the next generation(s).

In our model the first generations get no risk transferred from previous generations. However, they will be able to transfer some of the risk in their period to the next generations. These middle generations will assume risk from previous generations, but also be able to transfer risk to their followers. Finally, the last generations will assume risk from all previous generations as well as the full risk from their own investment period.

\section{Intergenerational diversification}

The returns of the different generations are dependent on both current and earlier periods stock market return. We illustrate this dependency by running OLS regressions where mean annual return, $\tilde{r}^{h}$, on the customer's initial investment is the left-hand side variable. We explain the return of generation $h=20$ by using two time periods of stock market return, $t=(1,20), r_{1,20}$ and $t=(21,40), r_{21,40}$ :

$$
\tilde{r}^{20}=\beta_{0}+\beta_{1} r_{1,20}+\beta_{2} r_{21,40}+\varepsilon
$$


Table 7 Intergenerational diversification

\section{Panel A}

Regression generation 20

$\beta_{0}$

$\beta_{1}$

$\beta_{2}$

Panel B

Regression generation 60

$\beta_{0}$

$\beta_{1}$

This table shows two panels. Panel A illustrates regression for generation 20. In panel B we show the regression for generation 60 . For each estimate of $\beta$, a 95 per cent confidence interval is stated.

For generation 60 the average annual return, $\tilde{r}^{60}$, is influenced not only by the return for period $(1,20)$ and $(21,40)$, but also by the return for the periods $(41,60)$ and $(61,80), r_{41,60}, r_{61,80}$, respectively:

$$
\tilde{r}^{60}=\beta_{0}+\beta_{1} r_{1,20}+\beta_{2} r_{21,40}+\beta_{3} r_{41,60}+\beta_{4} r_{61,80}+\varepsilon .
$$

We can interpret $\beta_{i}$ as how sensitive the customer's return is to the returns of the different time periods. The $\beta$ coefficient measures the correlation between the customer's return and the respective period. We expect the $\beta$ to decrease for more distant periods.

Panel $\mathrm{A}$ in Table 7 shows the regression for generation 20. If the stock market yields zero return we would expect a return at 3.35 per cent. If the average stock market return for the current period increases with 1 per cent, the customer's return increases with 0.14 per cent. The customer's return is more than 14 times more sensitive to current periods return than the previous period. $^{13}$

Generation 60 is dependent on 80 years stock market return, however, as shown in panel B in Table 7, the most important period is not surprisingly the current period. We see that the previous period is more important for generation 60 than for generation 20. The reason is that the bonus reserve increases with time.

\footnotetext{
${ }^{13}$ Since this regression is run on simulations the $t$-statistics are a function of numbers of simulations. With 100,000 simulations all the beta's are highly significant.
} 


\section{Sensitivities to the benchmark case}

Given the different characteristics of different L\&P insurance markets, one common model will, to a large degree have to build on averages. In Section 3, we show how some of the parameters vary across borders, in this section we will show how the level of different parameters will change the results of the model.

Changing the $\theta$ means changing the risk of the asset portfolio of the company. The higher the $\theta$, the higher the risk. When assuming more risk, the bonus reserve will be more frequently used as low asset returns (lower than the guaranteed rate) becomes more frequent. This leads to a lower average level of the bonus reserve. As early generations wish to limit the build-up of bonus reserves, they will benefit from higher $\theta$ at the cost of later generations. In Figure 5 we give results for different levels of $\theta$.

The finding that later generations benefit from a low $\theta$ may also give some explanation to low stock market exposure in most L\&P insurers. Intuitively one would think that companies should invest higher proportions in stocks to get closer to the optimal asset allocation for customers (see e.g. Døskeland and Nordahl (2008) for details). However, as companies prefer to satisfy new customers (the later generations) they may prefer a lower $\theta$.

A low spread between the risk-free rate and the guaranteed rate will lead to slower build-up of bonus reserves. This is due both to lower expected profits of

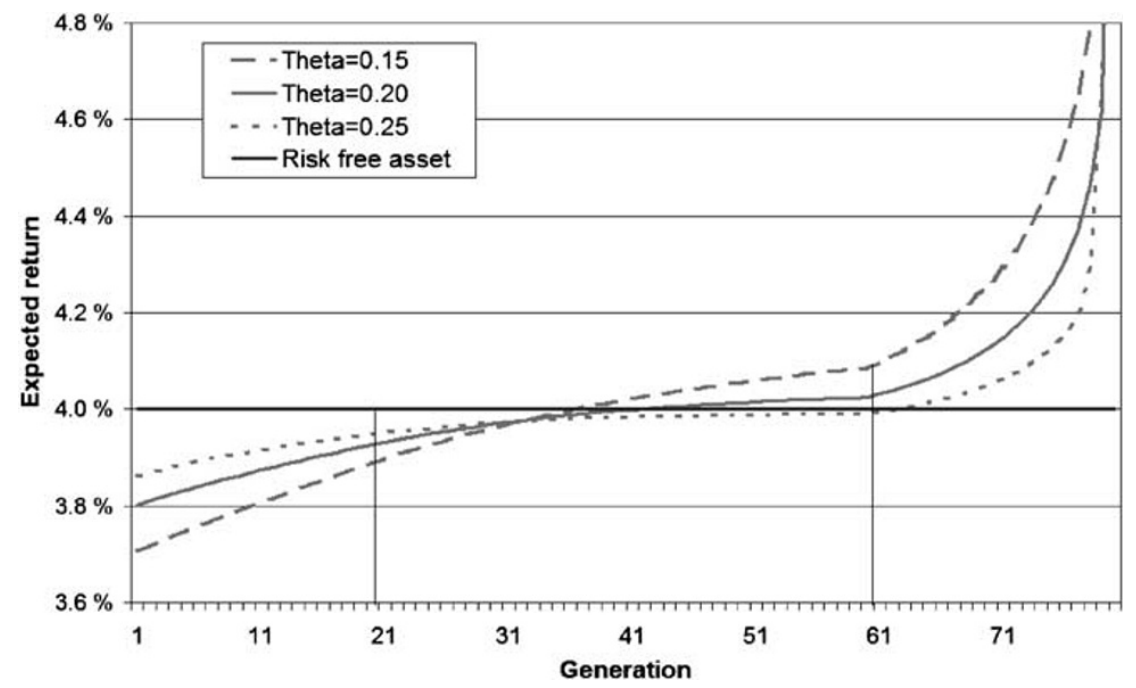

Figure 5. Sensitivity with respect to $\theta$. The effect of different alternative $\theta$ 's on the expected annual risk-adjusted return is illustrated in this figure. The benchmark case is $\theta=0.20$. 
the company (roughly equal to the spread) and to the lower $\delta$ (less favorable profit sharing to customers), the company will allow to compensate the higher guarantee. In Figure 6 we show that the intergenerational cross-subsidization decreases when $g$ is increased. The effect of decreasing $r$ will be similar to the effect of increasing $g$. We note, however, that $g=3$ per cent imply a spread of only 1 per cent, which is very low compared to the historical rates and leaves the life insurance contract close to a bond contract.

The build-up of bonus reserves can also be influenced more directly by changing $b$. In Figure 7 we show that a higher $b$ benefits the later generations. If $b$ goes towards zero, there will be no bonus reserves causing differences between generations.

The impact of changing the pay-out-ratio $p$ of the bonus reserve seems to be limited. In Figure 8 we show that the scenario with $p=50$ per cent is only marginally different from the benchmark case. Changing the payout ratio to $p=0$ per cent causes larger changes, this scenario yield lower returns to the first generations, while only the very last generations seem to benefit.

In Figure 9 we show the result that all generations benefit from a lower growth rate $v$. The first generations will still build up bonus reserves at the same pace as in the benchmark case. However, with a lower growth rate they will receive a larger proportion of the bonus reserve when the contract expires or in the case of low asset returns. The reason is that subsequent generations' mathematical reserves are now smaller and the first generations' share of the

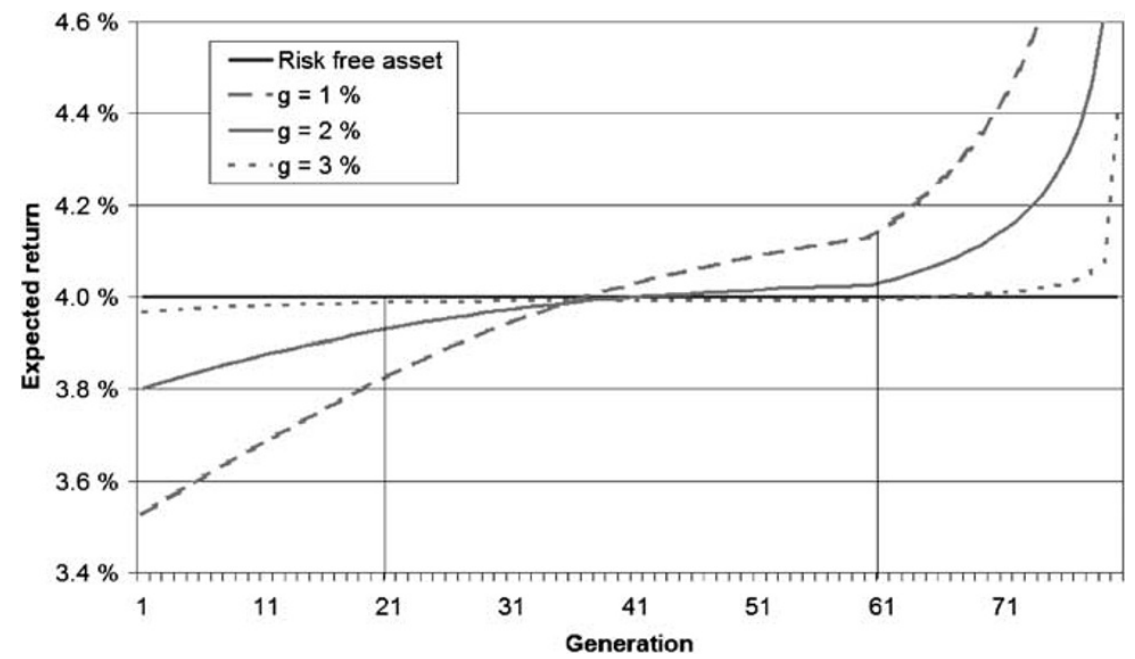

Figure 6. Sensitivity with respect to the guarantee $g$. The figure illustrates how different levels of the guarantee $g$ impact the expected annual risk-adjusted return. The benchmark case is $g=2$ per cent. 
40

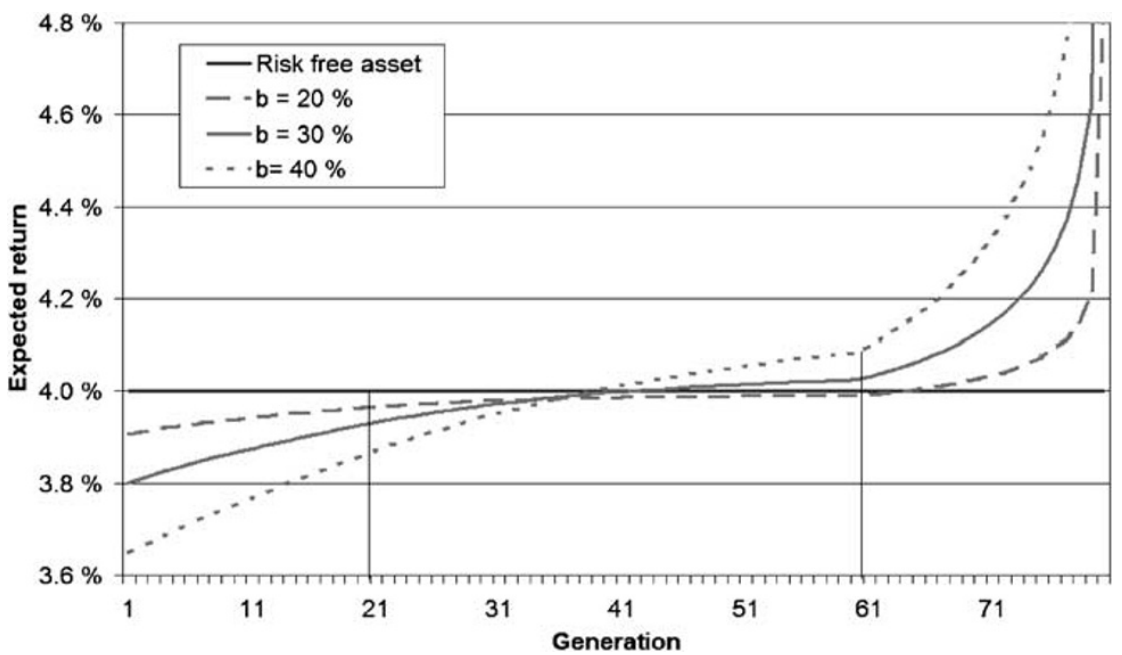

Figure 7. Sensitivity with respect to $b$. In this figure we show how the proportion of declared bonuses credited the bonus reserves, $b$, impacts the expected annual risk-adjusted return of the insurance contract. The benchmark case is $b=30$ per cent.

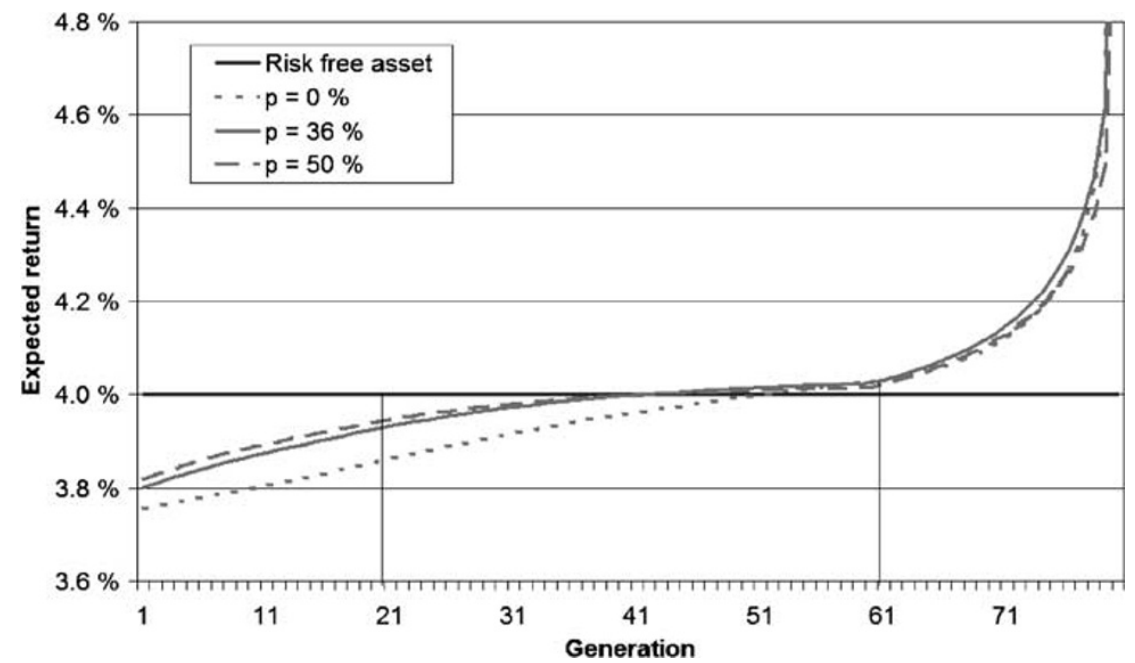

Figure 8. Sensitivity with respect to $p$. This figure illustrates how the payout ratio of bonus reserve, $p$, impacts the expected annual risk-adjusted return of the insurance contract. The benchmark case is $p=36$ per cent. 


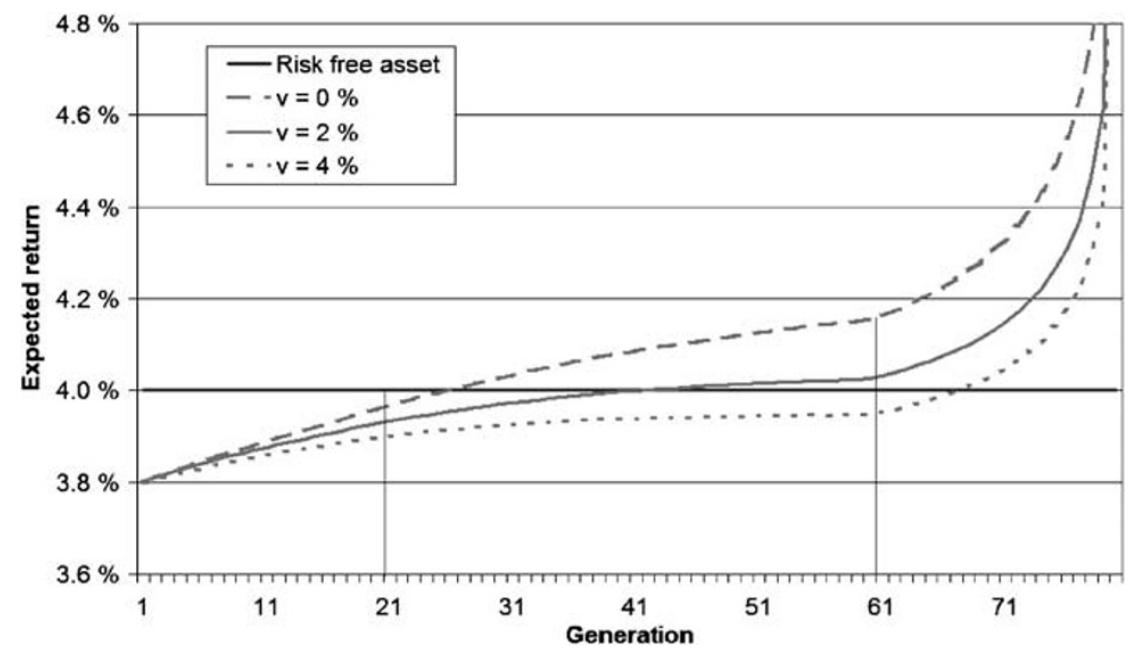

Figure 9. Sensitivity with respect to $v$. This figure illustrates how the growth rate of households' aggregate initial investments, $v$, impacts the expected annual risk-adjusted return of the insurance contract. The benchmark case is $v=2$ per cent.

total mathematical reserves is higher. This is only partially compensated for by a higher bonus reserve, as subsequent generations have only contributed to the build up of bonus reserves during a limited period.

Later generations will also receive this benefit, and in addition they will profit from the fact that the build-up of the ratio of bonus reserve to mathematical reserve now is faster, as the mathematical reserve grows more slowly. At the time of their initial investment their part of the bonus reserve will be larger per unit of investment, hence the "gift" from previous generation will have more impact. In Figure 9 we see that later generations get a higher benefit from a low growth rate than what the first generations do.

We note that the impact of the growth rate is the opposite of that of a payas-you-go pension system. While the pay-as-you-go system de facto produces a liability to be transferred from old generations to new ones, the guaranteed contracts produce an asset (the bonus reserve) to be transferred. Hence the guaranteed contracts may in some scenario work as a hedge of population growth risk of a pay-as-you-go system.

\section{Optimal portfolio choice}

In order to optimize individuals' portfolio choice as defined in the section 'The households', we run simulations under the real probability measure $P$. In Figure 10 we show how the expected return (given expectation for all 


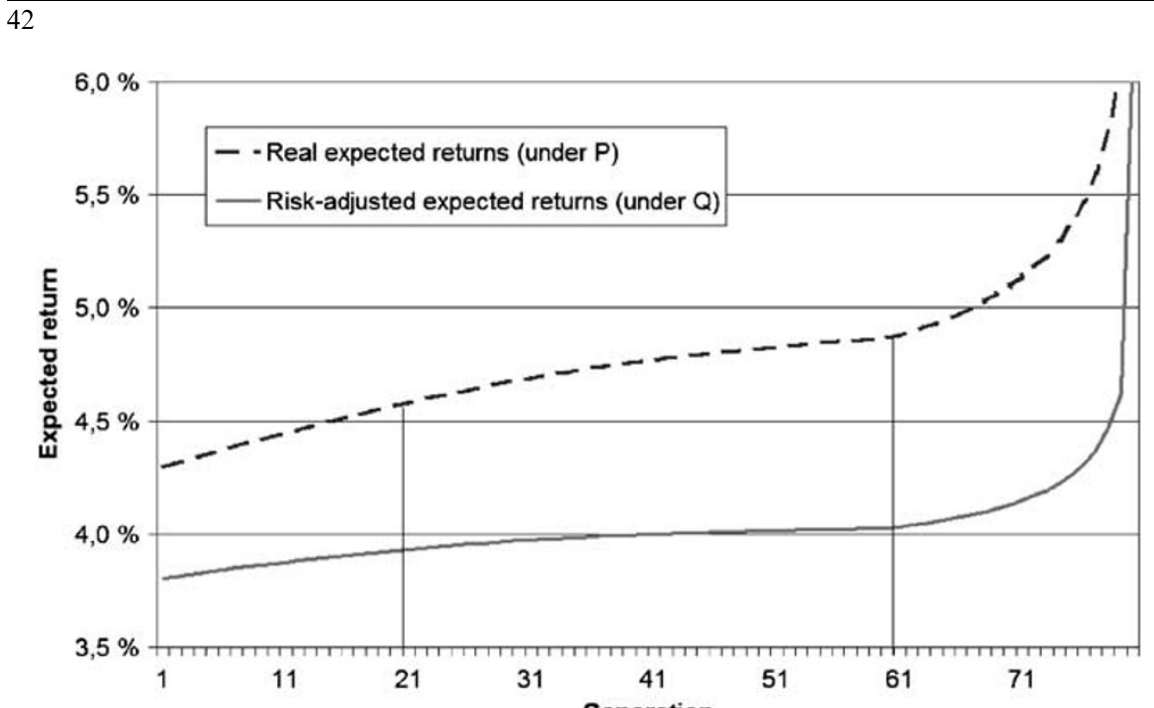

Figure 10. Real expected return for different generations. In this figure we compare the real expected annual return (under $P$ ) for different generations with the similar expected risk-adjusted return (under $Q$ ).

generations at time 1, see below) develops over generations compared to the risk-adjusted return (under the equivalent martingale measure $Q$ ). As previously explained in the section 'Result of the benchmark case', the standard deviation is higher for later generations. We note that the larger risk for later generations is compensated for by a larger risk premium measured by the difference between the return figures for each generation.

As we are interested in the life-cycle trend of the attractiveness of the contracts, we assume that the customers only know the expectation of the bonus reserve at time 1 . The customers do not know the realization of the bonus contract, hence they cannot start "timing" the contract by buying the contract only at high realizations of the bonus reserve. As we find that the expected return also depends on previous periods' market return, our expected return may be different from the expectation customers face at the time of investment. This makes sense in a setting where each generation is present behind a "veil of ignorance", they select a pension system (mix of e.g. public pensions, private pensions, and other savings products) to belong to some time ahead of the actual investment.

\section{Optimality for different generations in the benchmark case}

We maximize the household portfolio choice for each generation over three assets: the insurance asset, the risky asset, and the risk-free asset as shown in 


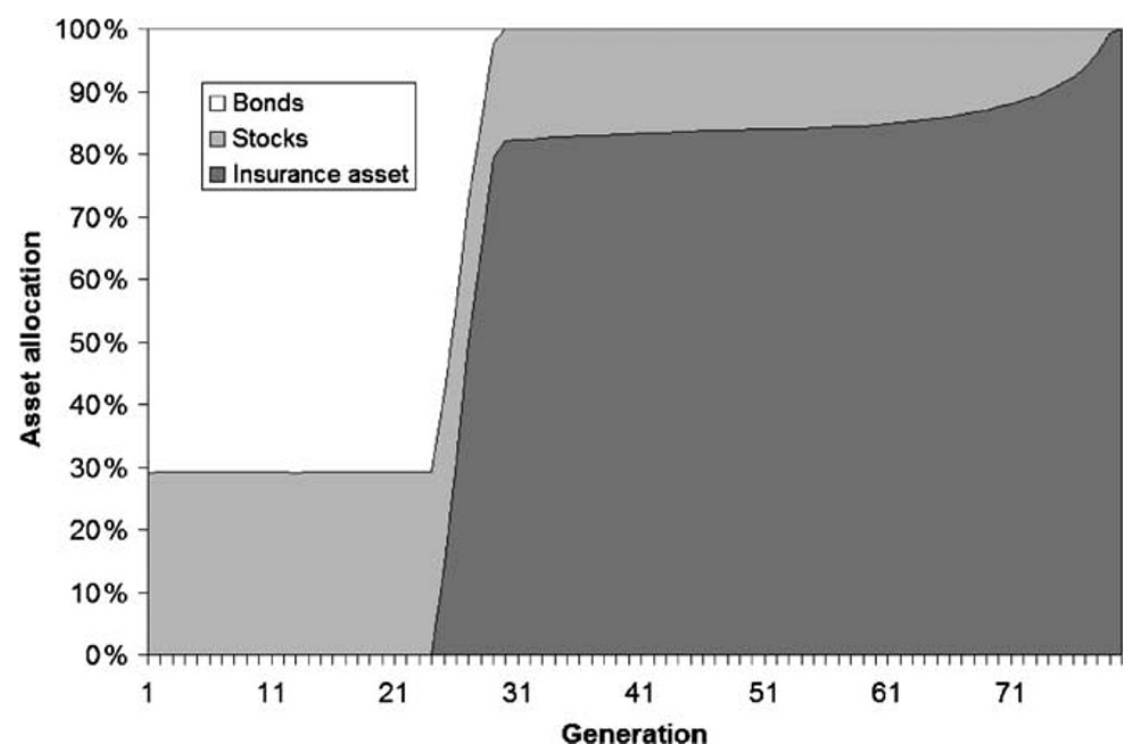

Figure 11. Optimal asset allocation for different generations, benchmark case. This figure shows the optimal allocation to different assets classes for the different generations 1-80, given our benchmark case relative risk aversion coefficient $\gamma=5$.

Eq. (22). We would expect the early generations to prefer direct investments in the risky and risk-free asset, while later generations will prefer to invest in the life asset due to the higher expected returns.

In Figure 11 we show that the first 25 generations will prefer no investment in the insurance asset. In this period the expected return under $Q$ is significantly below the risk-free rate (see Figure 3). The optimal allocation to the risky asset is approximately 29.2 per cent, which correspond to the Merton (1969) solution: ${ }^{14}$

$$
\omega_{S}^{*}=\frac{\mu-r}{\gamma \sigma^{2}}=\frac{4 \%}{5 \times 0.16^{2}}=31.25 \%
$$

where $\omega_{S}^{*}$ is the optimal allocation to the risky assets. The other parameters are shown in Table 4.

More surprisingly the optimal solution shows that for generation 25-42 it is optimal to invest in the insurance asset even though the risk-adjusted return is

\footnotetext{
${ }^{14}$ With the exception that due to the no rebalancing condition our solutions typically show a marginally lower investment in the risky asset.
} 
44

lower than the risk-free rate. The reason is that the diversification effects considered in the section 'Intergenerational diversification' benefits investments in the insurance asset combined with the risky asset. After generation 30 there is a slight increase in the optimal allocation to the insurance asset in later generations due to the increasing profitability of the life asset.

\section{Optimality for different levels of risk aversion}

The risk aversion parameter influences the optimal asset allocation. A lower risk aversion gives a higher allocation to the risky asset. For the earliest generations this drives down the allocation to the risk-free assets, while the generations after generation 25 mainly will reduce their exposure to the insurance asset. The optimal allocation in the case of $\gamma=3$ is shown in Figure 12.

The results for a risk aversion parameter equals 10, is shown in Figure 13. Now, the generations 25-40 want to keep a positive proportion in all three available assets. The investment in the risky asset is optimal in order to keep some diversification with the insurance asset. However, as the investor is now more risk-averse he wants to invest in the risk-free assets in order to keep the total risk down.



Figure 12. Optimal asset allocation for different generations with $\gamma=3$. This figure shows the optimal allocation to different asset classes, given the alternative $\gamma=3$. 


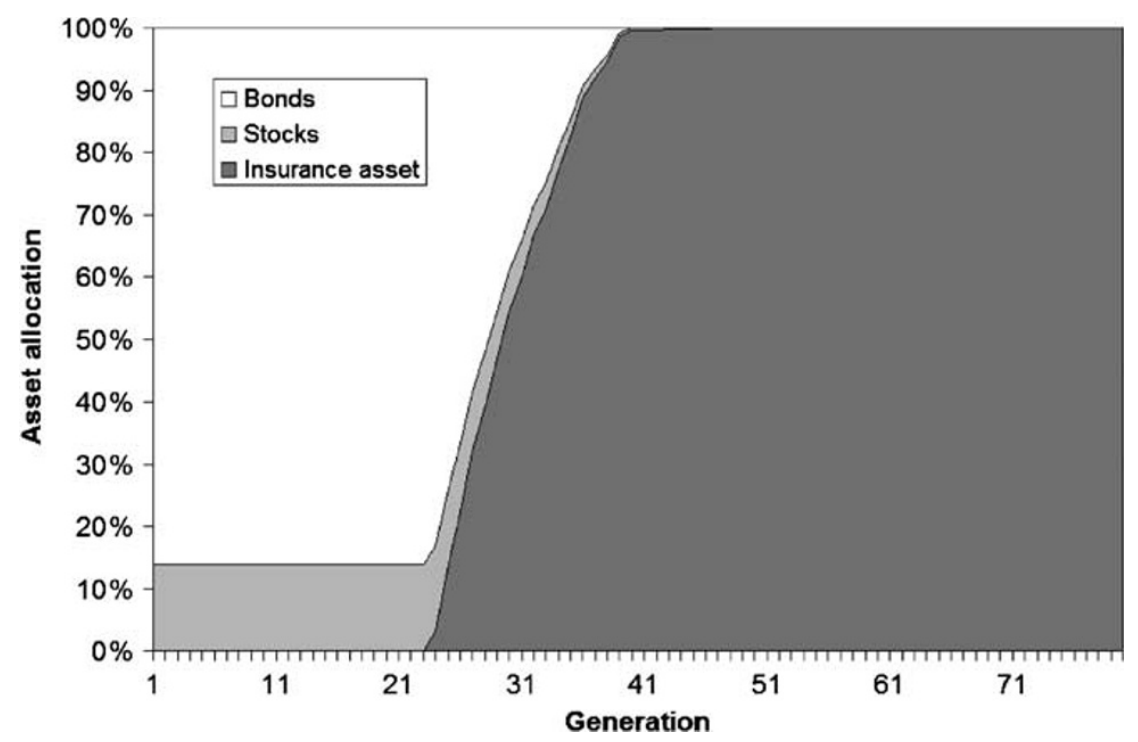

Figure 13. Optimal asset allocation for different generations with $\gamma=10$. This figure shows the optimal allocation to different asset classes, given the alternative $\gamma=10$.

\section{Conclusion}

In this paper we investigate the return of different generations investing in a guaranteed interest rate L\&P contract. We use a numerical simulation model over 80 generations with realistically calibrated parameters of a typical European guaranteed rate contract, with the assumption of correct pricing over the lifetime of the company. Our findings indicate that there exist a crosssubsidization from customers in early generations to customers in later generations. Furthermore, as returns for one generation depend also on return in previous periods, there is a time diversification effect built into the contract.

We also show that these effects are large enough to defend that a guaranteed rate contract is part of the optimal portfolio of the late generations. Hence our paper contributes to explaining why household invest in L\&P products even though they are not part of the optimal portfolio in a one-customer setting.

Future research in this area may expand our analysis to cover the question of whether private pensions should be included in a portfolio of pension systems. We have shown that there is a risk sharing effect between today's generation and earlier generation. This may add a dimension to today's system of pay-asyou-go and funded alternatives, where there is a risk sharing effect between today's generation and the younger generation. 


\section{Acknowledgements}

For helpful comments and suggestions, we thank two anonymous referees, Francisco Gomes, Espen Henriksen, Thore Johnsen, Snorre Lindset, Svein-Arne Persson, Eduard Ponds, José Víctor Ríos Rull, Kjetil Storesletten, and Knut K. Aase.

\section{References}

Borch, K. (1962) 'Equilibrium in a reinsurance market', Econometrica 30: 424-444.

Brennan, M.J. (1993) 'Aspects of insurance, intermediation and finance', Geneva Papers on Risk and Insurance Theory 18: 7-30.

Cocco, J.F., Gomes, F.J. and Maenhout, P.J. (2005) 'Consumption and portfolio choice over the life-cycle', The Review of Financial Studies 18: 491-533.

Consiglio, A., Saunders, D. and Zenios, S.A. (2006) 'Asset and liability management for insurance products with minimum guarantees: The UK case', Journal of Banking and Finance 30: 645-667.

Dammon, R.M., Spatt, C.S. and Zhang, H.H. (2004) 'Optimal asset location and allocation with taxable and tax-deferred investing', Journal of Finance 65: 999-1038.

Døskeland, T.M. and Nordahl, H.A. (2008) 'Optimal pension insurance design', Journal of Banking and Finance 32: 382-392.

Gomes, F.J. and Michaelides, A. (2005) 'Optimal life-cycle asset allocation: Understanding the empirical evidence', Journal of Finance 60: 869-904.

Grosen, A. and Jørgensen, P. (2000) 'Fair valuation of life insurance liabilities: The impact of interest rate guarantees, surrender options, and bonus policies', Insurance: Mathematics and Economics 26: 37-57.

Hansen, M. and Miltersen, K.R. (2002) 'Minimum rate of return guarantees: The Danish case', Scandinavian Actuarial Journal 4: 280-318.

Jensen, B.A. and Sørensen, C. (2001) 'Paying for minimum interest rate guarantees: Who should compensate who?', European Financial Management 7: 183-211.

Judd, K.L. (1998) Numerical Methods in Economics, Cambridge, MA: MIT Press.

Merton, R.C. (1969) 'Lifetime portfolio selection under uncertainty: The continuous time case', Review of Economics and Statistics 51: 247-257.

Miltersen, K.R. and Persson, S.-A. (2003) 'Guaranteed investment contracts: Distributed and undistributed excess return', Scandinavian Actuarial Journal 4: 257-279.

Yao, R. and Zhang, H.H. (2005) 'Optimal consumption and portfolio choices with risky housing and borrowing constraints', The Review of Financial Studies 18: 197-239. 